\title{
Chemical Components and Hepatoprotective Mechanism of Xwak Granule in Mice Treated with Acute Alcohol
}

\author{
Li Chen, ${ }^{1,2}$ Liu Liu, ${ }^{1}$ Rahima Abdulla, ${ }^{1}$ Xirali Tursun, ${ }^{1,2}$ Xuelei Xin $\mathbb{D}^{1},{ }^{1}$ \\ and Haji Akber Aisa $\mathbb{D}^{1}$ \\ ${ }^{1}$ Key Laboratory of Chemistry of Plant Resources in Arid Regions, \\ State Key Laboratory Basis of Xinjiang Indigenous Medicinal Plants Resource Utilization, \\ Xinjiang Technical Institute of Physics and Chemistry, Chinese Academy of Sciences, Urumqi 830011, China \\ ${ }^{2}$ University of Chinese Academy of Sciences, Beijing 100049, China \\ Correspondence should be addressed to Xuelei Xin; xinxl@ms.xjb.ac.cn and Haji Akber Aisa; haji@ms.xjb.ac.cn
}

Received 19 February 2020; Revised 24 July 2020; Accepted 3 August 2020; Published 28 September 2020

Academic Editor: Caigan Du

Copyright (C) $2020 \mathrm{Li}$ Chen et al. This is an open access article distributed under the Creative Commons Attribution License, which permits unrestricted use, distribution, and reproduction in any medium, provided the original work is properly cited.

\begin{abstract}
Objective. To evaluate the hepatoprotective mechanism of Xwak granule (Xwak) in treatment of mice with alcoholic liver injury via activating ERK/NF- $\kappa \mathrm{B}$ and Nrf/HO-1 signaling pathways. Methods. The chemical composition of Xwak was tested by liquid chromatography coupled with mass spectrometry (LC-MS). Herein, 1,1-diphenyl-2-picrylhydrazyl (DPPH) scavenging assay and 2,2-azino-bis (3-ethylbenzothiazoline-6-sulphonic acid (ABTS) radical tests were performed in vitro. The hepatoprotective effect of Xwak was assessed at different concentrations $(1.5,3$, and $6 \mathrm{~g} / \mathrm{kg})$ in a mouse model of alcoholic liver injury. Results. Totally, 48 compounds, including 16 flavonoids, 8 tannins, 9 chlorogenic acids, and 15 other compounds, were identified from Xwak. Xwak showed to have a satisfactory antioxidant activity in vitro. In a group of Xwak-treated mice, the serum levels of alanine transaminase (ALT), aspartate transaminase (AST), and alkaline phosphatase (ALP) were decreased compared with a group of the mouse model of alcoholic liver injury. In addition, the levels of antioxidant enzymes, such as glutathione peroxidase (GSH-PX), total superoxide dismutase (T-SOD), and catalase (CAT), were noticeably increased and the levels of malondialdehyde (MDA), tumor necrosis factor- $\alpha$ (TNF- $\alpha$ ), transforming growth factor- $\beta$ (TGF- $\beta$ ), and interleukin- 6 (IL- 6 ) were markedly reduced in the liver of mice. The state of oxidative stress in the mouse model of alcoholic liver injury was improved after treatment with Xwak. The improvement of inflammation-mediated disruption may conducive to the Xwak activity in the control of liver injury. The signals of p-ERK1/2, p-NF- $\kappa \mathrm{B}, \mathrm{COX}-2$, iNOS, CYP2E1, Nrf, and HO-1 were significantly induced in the liver of mice after treatment with Xwak. Conclusions. The abovementioned findings indicated that the hepatoprotective mechanism of Xwak could be achieved by activating ERK/NF- $\kappa \mathrm{B}$ and Nrf/HO-1 signaling pathways to alleviate oxidative stress and inflammatory.
\end{abstract}

\section{Introduction}

Alcoholic liver disease (ALD) is a term that encompasses the liver manifestations of alcohol overconsumption, including fatty liver, alcoholic hepatitis, and chronic hepatitis with liver fibrosis or cirrhosis [1]. The initial stage of ALD is liver damage caused by excessive consumption of alcohol, and in case of late treatment, it may further develop from alcoholic hepatitis to alcoholic fibrosis and finally deteriorate to alcoholic cirrhosis, and even hepatocellular carcinoma. ALD cause substantial morbidity and mortality, with around
500,000 deaths/year worldwide, and it adversely affects the quality of life of patients and their family members [2-4]. Prevention and treatment of ALD have become increasingly serious public health concerns worldwide. The underlying molecular mechanisms of ALD progression are still in progress, and previous research studies revealed that important factors influencing the progression of ALD are oxidative stress, lipid peroxidation, inflammation, and formation of toxic by-products [5-7]. In addition, oxidative stress plays a pivotal role in the occurrence and development of ALD. Dysregulated cytokine metabolism is another 
characteristic of ALD $[8,9]$. Therefore, it is highly urgent to find out new natural medicines to improve the progression of ALD according to the pathogenesis factors.

Natural plant extracts have significantly attracted scholars' attention due to their advantages of low toxicity, easy absorption, and multitarget action [10-12], while further effective natural medicines for ALD need to be explored. Xwak is a classic folk prescription, originating from national medical master, with a long history of clinical application in Uygur Medical Hospital, Xinjiang, China. Xwak has been registered in National Intellectual Property Administration (Beijing, China). It is mainly used in the treatment of liver diseases in ethnic medicine. Xwak is composed of six traditional Chinese herbs, including Artemisia rupestris L., Artemisia capillaris Thunb., Cichorium glandulosum Boiss. et Huet., Rosa rugosa Thunb., Rheum palmatum L., and Glycyrrhiza glabra L. These herbs contain anti-inflammatory effects, improve immune responses, and protect the liver [13-21]. We found that the main chemical components in Xwak are flavonoids, tannins, chlorogenic acid and phenolic acid, etc., and these components have been reported to possess protective functions against liver diseases $[10,22-26]$. However, the mechanism of hepatoprotection of Xwak in alcoholic liver injury has still remained elusive. In the present study, we analyzed the chemical components of Xwak and evaluated the hepatoprotective mechanism of Xwak in mice with alcoholic liver injury.

\section{Materials and Methods}

2.1. Materials and Reagents. Herein, 2,2-azino-bis(3-ethylbenzothiazoline-6-sulphonic acid) (ABTS) and 1,1diphenyl-2-picrylhydrazyl (DPPH) were purchased from Sigma-Aldrich Corporation (St. Louis, MO, USA). Silybin was obtained from Tianjin Tianshili Shengte Pharmaceutical Co., Ltd. (Tianjin, China). Kits required for measuring the levels of aspartate aminotransferase (AST), alanine aminotransferase (ALT), glutathione peroxidase (GSH-PX), total superoxide dismutase (T-SOD), catalase (CAT), malondialdehyde (MDA), lactate dehydrogenase (LDH), total cholesterol (TC), and triglyceride (TG) were purchased from Nanjing Jiancheng Bioengineering Institute (Nanjing, China). The alkaline phosphatase (ALP) was purchased from Shenzhen Mindray Biomedical Electronics Co., Ltd. The nitric oxide (NO) assay kit was brought from Beyotime Biotechnology (Shanghai, China). The enzyme-linked immunosorbent assay (ELISA) kits required for measuring the levels of interleukin-6 (IL-6), tumor necrosis factor- $\alpha$ (TNF$\alpha$ ), and transforming growth factor- $\beta$ (TGF- $\beta$ ) were purchased from MultiSciences (Hangzhou, China). The BCA protein assay kit was provided by Thermo Fisher Scientific (Waltham, MA, USA). The antibodies against p-ERK1/2, ERK1/2, p-NF- $\kappa$ B, nuclear factor-kappa B (NF- $\kappa$ B), COX-2, inducible NO synthase (iNOS), GAPDH, and $\beta$-actin were purchased from Cell Signaling Technology (Danvers, MA, USA). The antibody against cytochrome P450 2E1 (CYP2E1) was purchased from Millipore (Burlington, MA, USA). The antibodies against $\mathrm{Nrf} 2$ and $\mathrm{HO}-1$ were purchased from Abcam (Cambridge, UK). The secondary antibody was provided by Boster Biological Technology Co., Ltd. (Wuhan, China). ECL Plus ${ }^{\mathrm{TM}}$ was obtained from GE Healthcare (Chicago, IL, USA).

2.2. Plant Material and Preparation. Herein, Artemisia rupestris L., Artemisia capillaris Thunb., Cichorium glandulosum Boiss.et Huet., Rosa rugosa Thunb., Rheum palmatum L., and Glycyrrhiza glabra L. were collected from the Traditional Uygur Medicine Hospital (Xinjiang, China). These herbs were identified by Anwar Talip, the director of the pharmaceutical department. Voucher specimens were deposited in Xinjiang Technical Institute of Physics and Chemistry, Chinese Academy of Sciences (Xinjiang, China; voucher nos. Artemisia rupestris L. WY01223; Artemisia capillaris Thunb. WY02656; Cichorium glandulosum Boiss.et Huet. WY02310; Rosa rugosa Thunb. WY02101; Rheum palmatum L. WY02658; Glycyrrhiza glabra L. WY02657). The six medicinal materials were washed, dried, and crushed. According to the extraction method of the Xwak patent, 16 times of the amount of water was added and extracted twice, $2.5 \mathrm{~h}$ each time. The combined extract was concentrated under reduced pressure and then dried at $60^{\circ} \mathrm{C}$, crushed and sifted to obtain drug substance.

\subsection{Ultrahigh-Performance Liquid Chromatography Coupled with Mass Spectrometry (UHPLC-Q-Orbitrap-MS) Analysis}

2.3.1. Liquid Chromatography. UHPLC analyses were conducted using the UltiMate 3000 Rapid Separation LC (RSLC) system (Thermo Scientific Dionex, Waltham, MA, USA). The chromatographic separation column was InertSustain $\mathrm{C} 18(4.6 \times 250 \mathrm{~mm}, 5 \mu \mathrm{m})$, in addition to gradient elution with a mobile phase consisting of $0.2 \%$ formic acid in water (solvent A) and acetonitrile (solvent B) using the following gradients: $0-8 \mathrm{~min}(4-7 \% \mathrm{~B})$, 8-40 min (7-8\% B), 40-45 min (8-10\% B), 45-70 min $(10-13 \% \quad B), \quad 70-120 \mathrm{~min} \quad(13-16 \% \quad B), \quad 120-145 \mathrm{~min}$ $(16-28 \% \mathrm{~B}), 145-150 \mathrm{~min}(28-35 \% \mathrm{~B})$, and $150-170 \mathrm{~min}$ (35-50\% B); the flow rate was $1.0 \mathrm{~mL} / \mathrm{min}$, and volume of injection was $10 \mu \mathrm{L}$.

2.3.2. Mass Spectrometry. The MS was conducted with a Quadrupole-Orbitrap-HRMS (Thermo Fisher Scientific, Bremen, Germany). A high-sensitive heated electrospray ionization (HESI) probe was used to nebulize and ionize samples in both positive and negative ion modes. The MS acquisition was carried out in data-dependent acquisition (DDA) mode: the range of full-scan was from 100 to $1500 \mathrm{~m} /$ $z$ at 70,000 FWHM at $200 \mathrm{~m} / z$; MS/MS was set as 17,500 FWHM at $200 \mathrm{~m} / z$. The MS source was set as follows: heat temperature, $350^{\circ} \mathrm{C}$; capillary temperature, $300{ }^{\circ} \mathrm{C}$; source voltage, $3.2 \mathrm{kV}$ (positive) and $-2.8 \mathrm{kV}$ (negative); sheath gas flow, $40 \mathrm{arb}$; and auxiliary gas flow, $10 \mathrm{arb}$. The stepped normalized collision energy (NCE) was set to $20 \%, 40 \%$, and $60 \%$. The instrument was controlled by Xcalibur 4.0 (Thermo Fisher Scientific Inc., USA). 
2.4. Antioxidant Activity In Vitro. The DPPH scavenging assay was performed as described previously with minor modification [27]. DPPH is weighed accurately and dissolved with ethanol to prepare a solution with the concentration of $2 \mathrm{mM}$, stored it in a refrigerator, diluted to the concentration of $0.2 \mathrm{mM}$ DPPH solution before use. Next, $100 \mu \mathrm{L}$ sample with different concentrations was mixed with $100 \mu \mathrm{L}$ DPPH $(0.2 \mathrm{mM})$ solution, and the reaction mixture was incubated in the dark for $30 \mathrm{~min}$ at room temperature. Optical density (OD) of $515 \mathrm{~nm}$ was measured thereafter.

The ABTS radical assay is an excellent tool for determining the antioxidative activity, in which the radical is quenched to form ABTS radical complex. The ABTS radical scavenging activity was calculated according to Liu et al.'s method [28]. The ABTS solution was prepared by mixing with $7 \mathrm{mM}$ ABTS and $2.45 \mathrm{mM} \mathrm{K}_{2} \mathrm{~S}_{2} \mathrm{O}_{8}$ and allowing the mixture to stand in the dark at room temperature for at least $12 \mathrm{~h}$. The stock solution was diluted with ethanol to reach $0.68-0.72$ absorbance at $734 \mathrm{~nm}$ before use. The reaction was conducted with $16 \mu \mathrm{L}$ sample and $184 \mu \mathrm{L}$ ABTS working solution, and the mixed solution was reacted in the dark for $5 \mathrm{~min}$ at room temperature. Then, OD of $734 \mathrm{~nm}$ was measured.

Vitamin C was positive control in the ABTS and DPPH tests. The scavenging ability was calculated according to the following formula:

$$
\text { The scavenging ability }(\%)=\left[\frac{\left(\mathrm{OD}_{\text {control }}-\mathrm{OD}_{\text {sample }}\right)}{\left(\mathrm{OD}_{\text {control }}-\mathrm{OD}_{\text {blank }}\right)}\right] \times 100 \% \text {, }
$$

where $\mathrm{OD}_{\text {sample }}, \mathrm{OD}_{\text {blank, }}$, and $\mathrm{OD}_{\text {control }}$ represent the absorbance of the sample, the blank, and the control, respectively.

2.5. Animal Experiments. Five-week-old ICR male mice were purchased from the Experimental Animal Center of Xinjiang Medical University. The mice were housed in conventional cages under constant temperature and humidity with free access to food and water. All experimental procedures were approved by the Xinjiang Uygur Medicine Research Institute (approval no. SYXK 2016-0003).

The mice were allowed to acclimate for one week prior to experiments. Then, a total of 48 mice were randomly divided into 6 groups ( $n=8$ for each group) as follows: control (Cont), alcoholic liver injury model group $(\mathrm{EtOH})$, positive control (SILY), low-dose of Xwak (XL), medium-dose of Xwak (XM), and high-dose of Xwak $(\mathrm{XH})$. In the Cont and EtOH groups, mice were given the same volume of distilled water. In the SILY group, mice were orally treated with silybin $(79.1 \mathrm{mg} / \mathrm{kg})$. In the three dose-based groups, mice were orally administered with a low-dose $(1.5 \mathrm{~g} / \mathrm{Kg})$, medium-dose $(3 \mathrm{~g} / \mathrm{Kg})$, and highdose $(6 \mathrm{~g} / \mathrm{Kg})$ of Xwak for 4 weeks. Additionally, $1 \mathrm{~h}$ after the last administration, mice in the Cont group were intraperitoneally injected with the same volume of saline, and in the other groups, mice were intraperitoneally injected with $56 \%$ ethanol at $5 \mathrm{~mL} / \mathrm{kg}$ to induce hepatic injury as reported previously $[29,30]$. Then, the mice were killed 5 hours later, and the serum and liver were collected for the subsequent experiments.

2.6. Blood Biochemical Analysis. The mouse blood was collected at the end of experiment. Then, serum was obtained by centrifugation at $3000 \mathrm{rpm}$ for $10 \mathrm{~min}$. The serum levels of AST, ALT, and ALP in a mouse model of alcoholic liver injury were detected by 7100 Hitachi automatic biochemical analyzer (Hitachi, Tokyo, Japan).

2.7. Detection of Biochemical Markers in Liver Tissue. The liver tissue of mice was accurately weighed, and liver tissue homogenate in saline or phosphate-buffered saline (PBS) buffer was prepared to detect the biochemical markers. The protein concentration of liver tissue homogenate was detected by BCA kit. The levels of AST, ALT, LDH, NO, TC, TG, GSHPX, T-SOD, CAT, MDA, IL- 6, TNF- $\alpha$, and TGF- $\beta$ were detected according to the manufacturer's instructions of kits.

2.8. Western Blot Analysis. The liver tissues were homogenized in lysis buffer, and the supernatant was collected after centrifugation at $13000 \mathrm{rpm}$ for $10 \mathrm{~min}$. The protein concentration was assayed by BCA kit. Equal amount of protein from each sample was subjected to sodium dodecyl sulfatepolyacrylamide gel electrophoresis (SDS-PAGE), and then the protein was transferred onto a polyvinylidene fluoride (PVDF) membrane. The membrane was blocked with 5\% milk buffer or $5 \%$ bovine serum albumin (BSA) buffer for $1 \mathrm{~h}$. The primary antibodies against p-ERK1/2, ERK1/2, COX-2, p-NF- $\kappa \mathrm{B}, \mathrm{NF}-\kappa \mathrm{B}$, iNOS, CYP2E1, Nrf2, HO-1, $\mathrm{GAPDH}$, and $\beta$-actin were used to detect the corresponding signals overnight at $4^{\circ} \mathrm{C}$. After that, the membranes were incubated with horseradish peroxidase (HRP)-conjugated secondary antibody for $1 \mathrm{~h}$. The specific band was detected with the chemiluminescent reagent (ECL) by Bio-Rad gel imaging system (Bio-Rad Laboratories, Hercules, CA, USA).

2.9. Histological Evaluation. The fresh liver of mice was fixed with $10 \%$ neutral formalin solution, dehydrated (TP1020, LEICA, Germany), paraffin embedded (KD-BM/BLII, Zhejiang, China), sliced (RM2235, LEICA, Germany), and hematoxylin eosin (HE) stained for histopathological examination [31].

2.10. Statistical Analysis. The data were expressed as the mean \pm standard deviation (SD). The statistical difference between the groups was calculated with one-way analysis of variance (ANOVA). The data were statistically analysed by GraphPad Prism 6.0 software (GraphPad Software Inc., La Jolla, CA, USA). $p<0.05$ was considered statistically significant.

\section{Results}

3.1. LC-MS Analysis of Xwak. Totally, 48 compounds, including 16 flavonoids, 8 tannins, 9 chlorogenic acids, and 15 other compounds, were identified from Xwak by LC-MS 
with the help of retention time $\left(t_{R}\right)$, predicted formula and errors, fragmentation behavior, and the reference standards (Table 1).

3.2. Antioxidant Activity of Xwak In Vitro. DPPH and ABTS were used to detect the antioxidant activity of the Xwak. The change of color caused by the reaction between antioxidants and radical can be observed at a specific wavelength. The antioxidant activity of Xwak was shown as the half maximal inhibitory concentration $\left(\mathrm{IC}_{50}\right)$. In DPPH radical scavenging assay (Table 2), results of the present study revealed that the $\mathrm{IC}_{50}$ value of Xwak was $21.02 \pm 0.33 \mu \mathrm{g} / \mathrm{mL}$. In ABTS radical scavenging assay (Table 3 ), $\mathrm{IC}_{50}$ value of Xwak was $14.39 \pm 0.30 \mu \mathrm{g} / \mathrm{mL}$. Moreover, the $\mathrm{IC}_{50}$ value of the positive control on DPPH and ABTS was 5.18 \pm 0.29 and $3.26 \pm 0.36 \mu \mathrm{g} / \mathrm{mL}$, respectively. These results indicated that Xwak has a satisfactory antioxidant activity in vitro.

3.3. Effects of Xwak on Alcoholic Liver Injury. The protective effects of Xwak on mice with alcoholic liver injury were evaluated using serum levels of AST, ALT, and ALP. As depicted in Figure 1, compared with the Cont group, the serum levels of AST, ALT, and ALP were significantly $(p<0.05)$ elevated in the EtOH group, indicating status of liver dysfunction in the EtOH group. The serum level of ALP was noticeably $(p<0.05)$ reduced in SILY, XM, and XH groups. The decreased serum levels of ALT and AST were also noted in the SILY group $(p<0.05)$ and XH group $(p<0.05)$. The abovementioned results indicated that Xwak could ameliorate the alcohol-induced liver injury in mice.

The effects of Xwak on liver function were examined by measuring the levels of AST, ALT, NO, and LDH. As displayed in Figure 2, the levels of AST and ALT were markedly enhanced in the EtOH group $(p<0.05)$. It also was noted that the level of AST was significantly reduced by Xwak and silybin in SILY, XL, XM, and XH groups $(p<0.05)$. The level of ALT was also noticeably decreased in SILY and XH groups $(p<0.05)$.

As shown in Figure 3, the level of NO was significantly increased in the EtOH group $(p<0.05)$ compared with that in the Cont group. The elevation of the level of NO could be attenuated by supplementation of Xwak, especially at XM and XH groups $(p<0.05)$. The level of LDH was increased in the $\mathrm{EtOH}$ group compared with that in the Cont group, while the difference was not statistically significant. The level of LDH was decreased by Xwak in the XH group $(p<0.05)$.

3.4. Effects of Xwak on Antioxidant Activities in Liver. Several antioxidant enzymes were examined as parameters to detect the level of oxidative stress in the liver of mice (Figure 4). The levels of GSH-PX, T-SOD, and CAT were markedly reduced in the EtOH group $(p<0.05)$. However, the level of MDA was remarkably increased in the EtOH group $(p<0.05)$ compared with that in the Cont group. The levels of T-SOD and CAT were significantly increased in the three groups of XL, XM, and $\mathrm{XH}$ in mice with alcoholic liver injury $(p<0.05)$. The level of GSH-PX was notably increased in XL and XH groups $(p<0.05)$ compared with that in the EtOH group. Additionally, the level of MDA was noticeably decreased in the three groups of XL, XM, and XH $(p<0.05)$. These data demonstrated that Xwak has an acceptable antioxidant capacity in vivo.

3.5. Effects of Xwak on Lipid Levels in Liver. Herein, the effects of Xwak on the levels of TC and TG were measured in the liver of mice. As depicted in Figure 5, the levels of TC and TG were increased in the EtOH group compared with those in the Cont group, while the difference was not statistically significant. In mice that treated with Xwak, the level of TC was markedly reduced in the XM group and $\mathrm{XH}$ group $(p<0.05)$. A remarkable decrease of TG level was also noted in the XM group $(p<0.05)$. A trend of insignificant effect of Xwak on the levels of TC and TG was observed in other administration-based groups. These results indicated that Xwak may have a positive effect on hepatic lipid level.

3.6. Effects of Xwak on Levels of Cytokines in Liver. As shown in Figure 6, the levels of TNF- $\alpha$ and TGF- $\beta$ in the EtOH group were significantly elevated compared with those in the Cont group $(p<0.05)$. However, the levels of TNF- $\alpha$ and TGF- $\beta$ were significantly reduced in the XM and XH groups $(p<0.05)$. The level of IL-6 in the EtOH group was higher than that in the Cont group, whereas the difference was not statistically significant. The increased level of IL-6 in mice with alcoholic liver injury was attenuated after treatment with silybin and Xwak.

3.7. Effects of Xwak on the Expression Levels of ERK, P38MAPK, NF- $\kappa B$, iNOS, COX-2, CYP2E1, Nrf, and HO- 1 in the Liver of Mice. We further explored the underlying hepatoprotective mechanism of Xwak in mice with alcoholic liver injury. The results of Western blotting showed that the expression levels of $\mathrm{p}-\mathrm{ERK} 1 / 2, \mathrm{p}-\mathrm{NF}-\kappa \mathrm{B}, \mathrm{COX}-2$, iNOS, and CYP2E1 were elevated in the EtOH group compared with those in the Cont group (see Figure 7). The increased expression levels of p-ERK1/2, p-NF- $\kappa \mathrm{B}, \mathrm{COX}-2$, iNOS, and CYP2E1 were significantly attenuated after treatment with silybin and Xwak. Moreover, the expression levels of Nrf and HO-1 were noticeably reduced in the EtOH group compared with those in the Cont group. The reduced expression level of Nrf was significantly improved after treatment with silybin and Xwak in all groups (SILY, $\mathrm{XL}, \mathrm{XM}$, and $\mathrm{XH}$ groups). The expression level of $\mathrm{HO}-1$ was also improved in SILY and XH groups. Our results indicated that Xwak is able to decrease activities of ERK and improve activities of $\mathrm{Nrf} / \mathrm{HO}-1$ signaling pathways in mice with alcoholic liver injury.

3.8. Effects of Xwak on Liver Histopathology. No obvious pathological changes were found in the pathological sections of liver tissue in each group (see Figure 8). 
TABLE 1: Identification of extracts from Xwak using UHPLC-Q-Orbitrap MS.

\begin{tabular}{|c|c|c|c|c|c|c|}
\hline No. & $\begin{array}{l}\text { Retention time } \\
\quad(\min )\end{array}$ & $\begin{array}{l}\text { Exact mass } \\
\qquad(\mathrm{m} / \mathrm{z})\end{array}$ & $\begin{array}{l}\text { Molecular } \\
\text { formula }\end{array}$ & $\begin{array}{l}\text { Error } \\
(\mathrm{ppm})\end{array}$ & $\mathrm{MS}^{2}$ data $(m / z)$ & Identification \\
\hline 1 & 2.74 & 195.05034 & $\mathrm{C}_{6} \mathrm{H}_{12} \mathrm{O}_{7}$ & 2.10 & $129(20), 75(100)$ & Gluconic acid \\
\hline 2 & 2.89 & 341.10883 & $\mathrm{C}_{12} \mathrm{H}_{22} \mathrm{O}_{11}$ & 2.89 & 179(5), 113(20), 89(40), 71(70), 59(100) & Caffeic acid-glucoside \\
\hline 3 & 2.92 & 191.05537 & $\mathrm{C}_{7} \mathrm{H}_{12} \mathrm{O}_{6}$ & 1.88 & $93(20), 85(100)$ & Quinic acid \\
\hline 4 & 3.36 & 133.01324 & $\mathrm{C}_{4} \mathrm{H}_{6} \mathrm{O}_{5}$ & 0.67 & $115(80), 71(100)$ & Malic acid \\
\hline 5 & 4.47 & 191.01901 & $\mathrm{C}_{6} \mathrm{H}_{8} \mathrm{O}_{7}$ & 2.01 & $129(10), 111(100)$ & Critic acid \\
\hline 6 & 5.41 & 343.06739 & $\mathrm{C}_{14} \mathrm{H}_{16} \mathrm{O}_{10}$ & 4.29 & 191(80), 169(70), 125(95), 107(100) & Galloyle-quinic acid \\
\hline 7 & 5.87 & 481.06250 & $\mathrm{C}_{20} \mathrm{H}_{17} \mathrm{O}_{14}$ & 2.54 & $\begin{array}{c}301(100), 275(60), 257(30), 229(40) \\
185(20)\end{array}$ & HHDP-glucoside \\
\hline 8 & 5.91 & 331.0674 & $\mathrm{C}_{13} \mathrm{H}_{16} \mathrm{O}_{10}$ & 3.93 & $169(80), 125(100)$ & Galloyle-glucoside \\
\hline 9 & 8.78 & 169.01338 & $\mathrm{C}_{7} \mathrm{H}_{6} \mathrm{O}_{5}$ & 1.36 & $125(100)$ & Gallic acid \\
\hline 10 & 9.21 & 343.10367 & $\mathrm{C}_{14} \mathrm{H}_{16} \mathrm{O}_{10}$ & 3.49 & 191(100), 169(70), 125(85), 107(90) & Galloyle-quinic acid \\
\hline 11 & 9.29 & 483.07867 & $\mathrm{C}_{20} \mathrm{H}_{20} \mathrm{O}_{14}$ & 3.60 & $331(10), 169(60), 125(100), 107(30)$ & Digalloyl-glucoside \\
\hline 12 & 12.05 & 483.07825 & $\mathrm{C}_{20} \mathrm{H}_{20} \mathrm{O}_{14}$ & 2.73 & $331(10), 169(60), 125(100), 107(20)$ & Digalloyl-glucoside \\
\hline 13 & 13.63 & 483.07828 & $\mathrm{C}_{20} \mathrm{H}_{20} \mathrm{O}_{14}$ & 2.79 & $331(15), 169(60), 125(100), 107(20)$ & Digalloyl-glucoside \\
\hline 14 & 15.44 & 153.01847 & $\mathrm{C}_{7} \mathrm{H}_{6} \mathrm{O}_{4}$ & 1.52 & $109(100)$ & 2,3-Dihydroxybenzoic acid \\
\hline 15 & 17.98 & 353.08796 & $\mathrm{C}_{16} \mathrm{H}_{18} \mathrm{O}_{9}$ & 3.53 & $\begin{array}{c}191(80), 179(30), 161(10), 135(100) \\
85(30)\end{array}$ & 5-O-caffeoylquinic acid \\
\hline 17 & 18.01 & 483.07819 & $\mathrm{C}_{20} \mathrm{H}_{20} \mathrm{O}_{14}$ & 2.31 & $313(25), 169(80), 125(100), 107(30)$ & Digalloyl-glucoside \\
\hline 18 & 22.76 & 339.07232 & $\mathrm{C}_{15} \mathrm{H}_{16} \mathrm{O}_{9}$ & 3.72 & $177(100), 133(30), 105(20), 89(20)$ & Esculin hydrate \\
\hline 19 & 35.40 & 177.01860 & $\mathrm{C}_{9} \mathrm{H}_{6} \mathrm{O}_{4}$ & 2.06 & $149(20), 133(90), 105(50), 89(40)$ & Esculetin \\
\hline 20 & 35.94 & 353.08795 & $\mathrm{C}_{16} \mathrm{H}_{18} \mathrm{O}_{9}$ & 3.47 & 191(100), 161(5), 127(5), 93(15), 85(30) & 3-O-caffeoyl quinic acid \\
\hline 21 & 38.64 & 353.08807 & $\mathrm{C}_{16} \mathrm{H}_{18} \mathrm{O}_{9}$ & 3.86 & $\begin{array}{c}\text { 191(40), 179(30), 173(50), 161(5) } \\
135(100), 127(5), 93(50)\end{array}$ & 4-O-caffeoyl quinic acid \\
\hline 22 & 64.99 & 367.1045 & $\mathrm{C}_{17} \mathrm{H}_{20} \mathrm{O}_{9}$ & 2.97 & $\begin{array}{c}\text { 191(100), 193(20), 173(10), 155(5), } \\
134(60), 93(80)\end{array}$ & Feruloylquinic acid \\
\hline 23 & 65.23 & 515.11951 & $\mathrm{C}_{25} \mathrm{H}_{24} \mathrm{O}_{12}$ & 1.97 & $\begin{array}{l}\text { 353(10), 191(95), 179(50), 161(15) } \\
\text { 135(100), } 85(20)\end{array}$ & $\begin{array}{l}\text { 1,3-Di-O-caffeoyl quinic } \\
\text { acid }\end{array}$ \\
\hline 24 & 65.24 & 635.08911 & $\mathrm{C}_{27} \mathrm{H}_{24} \mathrm{O}_{18}$ & 1.92 & $\begin{array}{c}465(50), 313,(40), 169(95), 125(100) \\
107(20)\end{array}$ & Tri-O-galloyl-glucoside \\
\hline 25 & 66.52 & 469.0049 & $\mathrm{C}_{21} \mathrm{H}_{30} \mathrm{O}_{15}$ & 1.80 & 300(100), 271(20), 229(30), 185(10) & Ellagic acid blactone \\
\hline 26 & 97.66 & 300.99887 & $\mathrm{C}_{14} \mathrm{H}_{6} \mathrm{O}_{8}$ & 3.24 & $284(10), 245(20), 229(30), 185(10)$ & Ellagic acid \\
\hline 27 & 98.11 & 463.08832 & $\mathrm{C}_{21} \mathrm{H}_{20} \mathrm{O}_{12}$ & 2.41 & $301(100) 175(20), 151(50), 107(30)$ & Quercetin-7-O-glucoside \\
\hline 28 & 102.55 & 463.08832 & $\mathrm{C}_{21} \mathrm{H}_{20} \mathrm{O}_{12}$ & 2.63 & $\begin{array}{c}300(70), 271(100), 255(50), 243(40) \\
227(20), 151(20)\end{array}$ & Hyperoside \\
\hline 29 & 103.47 & 609.14618 & $\mathrm{C}_{27} \mathrm{H}_{30} \mathrm{O}_{16}$ & 1.92 & $\begin{array}{c}300(90), 271(100), 255(50), 243(30) \\
227(10), 151(20)\end{array}$ & Rutin \\
\hline 30 & 106.13 & 447.0934 & $\mathrm{C}_{21} \mathrm{H}_{20} \mathrm{O}_{11}$ & 2.89 & 285(100), 256(20), 227(20), 133(30) & Luteolin-O-glucoside \\
\hline 31 & 106.41 & 477.06766 & $\mathrm{C}_{21} \mathrm{H}_{18} \mathrm{O}_{13}$ & 2.71 & $\begin{array}{c}301(100), 255(30), 227(10), 179(35) \\
151(60), 107(30)\end{array}$ & Quercetin-3-O-glucuronide \\
\hline 32 & 107.45 & 463.08844 & $\mathrm{C}_{21} \mathrm{H}_{20} \mathrm{O}_{12}$ & 2.89 & $\begin{array}{c}300(90), 271(100), 255(50), 243(30) \\
227(20), 151(10)\end{array}$ & Quercetin-3-O-glucoside \\
\hline 33 & 107.37 & 681.13068 & $\mathrm{C}_{29} \mathrm{H}_{30} \mathrm{O}_{16}$ & 1.36 & 351(40), 299(60), 193(40), 113(80) & Tricin-7-O-diglucuronide \\
\hline 34 & 108.05 & 463.08847 & $\mathrm{C}_{21} \mathrm{H}_{20} \mathrm{O}_{12}$ & 2.95 & $\begin{array}{c}300(80), \text { 271(100), } 255(50), 243(30) \\
227(20), 151(15)\end{array}$ & Quercetin-3'-O-glucoside \\
\hline 35 & 115.70 & 433.07784 & $\mathrm{C}_{20} \mathrm{H}_{18} \mathrm{O}_{11}$ & & $\begin{array}{c}300(90), 271(100), 255(50), 243(30) \\
227(20), 151(15)\end{array}$ & Quercetin-3-O-arabinoside \\
\hline 36 & 116.39 & 515.11957 & $\mathrm{C}_{25} \mathrm{H}_{24} \mathrm{O}_{12}$ & 2.27 & $\begin{array}{c}353(10), 191(50), 179(50), 173(55) \\
161(25), 135(100), 93(40)\end{array}$ & $\begin{array}{l}\text { 3,4-Di-O-caffeoyl quinic } \\
\text { acid }\end{array}$ \\
\hline 37 & 120.79 & 515.11963 & $\mathrm{C}_{25} \mathrm{H}_{24} \mathrm{O}_{12}$ & 2.38 & $\begin{array}{c}353(10), 191(50), 179(50), 173(55) \\
161(25), 135(100)\end{array}$ & $\begin{array}{l}\text { 3,5-Di-O-caffeoyl quinic } \\
\text { acid }\end{array}$ \\
\hline 38 & 129.63 & 447.09344 & $\mathrm{C}_{21} \mathrm{H}_{20} \mathrm{O}_{11}$ & 2.80 & $\begin{array}{c}284(50), 255(90), 227(100), 183(20) \\
151(5)\end{array}$ & Kampferol-O-glucoside \\
\hline 39 & 130.18 & 447.09344 & $\mathrm{C}_{21} \mathrm{H}_{20} \mathrm{O}_{11}$ & 2.81 & $\begin{array}{c}300(85), 271(100), 255(55), 243(30) \\
227(15), 179(10), 151(20)\end{array}$ & $\begin{array}{l}\text { Quercetin-3-O- } \\
\text { rhahmanoside }\end{array}$ \\
\hline 40 & 136.16 & 515.11938 & $\mathrm{C}_{25} \mathrm{H}_{24} \mathrm{O}_{12}$ & 1.90 & $\begin{array}{c}353(20), 191(40), 179(45), 173(70) \\
161(20), 135(100)\end{array}$ & $\begin{array}{l}\text { 4,5-Di-O-caffeoyl quinic } \\
\text { acid }\end{array}$ \\
\hline 41 & 140.94 & 431.09863 & $\mathrm{C}_{21} \mathrm{H}_{20} \mathrm{O}_{10}$ & 3.15 & $\begin{array}{c}284(50), 255(100), 227(90), 211(20) \\
183(10)\end{array}$ & Kampferol-O-rhamnoside \\
\hline
\end{tabular}


TABLE 1: Continued.

\begin{tabular}{|c|c|c|c|c|c|c|}
\hline No. & $\begin{array}{l}\text { Retention time } \\
(\min )\end{array}$ & $\begin{array}{l}\text { Exact mass } \\
(\mathrm{m} / \mathrm{z})\end{array}$ & $\begin{array}{c}\text { Molecular } \\
\text { formula }\end{array}$ & $\begin{array}{l}\text { Error } \\
(\mathrm{ppm})\end{array}$ & $\mathrm{MS}^{2}$ data $(m / z)$ & Identification \\
\hline 42 & 141.43 & 417.11948 & $\mathrm{C}_{21} \mathrm{H}_{22} \mathrm{O}_{9}$ & 3.51 & $\begin{array}{c}255(100), 180(80), 153(30), 148(70) \\
135(80), 119(95), 108(50), 91(100)\end{array}$ & $\begin{array}{l}\text { Isoliquiritigenin-O- } \\
\text { glucoside }\end{array}$ \\
\hline 43 & 145.43 & 529.13531 & $\mathrm{C}_{26} \mathrm{H}_{26} \mathrm{O}_{12}$ & 2.38 & $\begin{array}{c}367(5), 193(20), 179(5), 173(100) \\
161(20), 134(50), 93(70)\end{array}$ & $\begin{array}{c}\text { 4-O-feruloyl, 5-O-caffeoy } \\
\text { quinic acid }\end{array}$ \\
\hline 44 & 149.76 & 285.04050 & $\mathrm{C}_{15} \mathrm{H}_{10} \mathrm{O}_{6}$ & 3.98 & $257(5), 243(5), 217(5), 131(100)$ & Luteolin \\
\hline 45 & 150.45 & 253.05049 & $\mathrm{C}_{15} \mathrm{H}_{10} \mathrm{O}_{4}$ & 3.77 & $225(100), 210(10), 181(5)$ & Daidzein \\
\hline 46 & 150.53 & 431.09839 & $\mathrm{C}_{21} \mathrm{H}_{20} \mathrm{O}_{10}$ & 2.59 & 269(100), 240(10), 225(40), 181(10) & Apigenin-O-gucoside \\
\hline 47 & 155.98 & 247.13373 & $\mathrm{C}_{15} \mathrm{H}_{20} \mathrm{O}_{3}$ & 3.47 & $\begin{array}{c}231(5), 203(100), 188(10), 163(20) \\
109(30)\end{array}$ & Rupestonic acid \\
\hline 48 & 157.41 & 299.05627 & $\mathrm{C}_{16} \mathrm{H}_{12} \mathrm{O}_{6}$ & 4.21 & 284(100), 256(80), 151(10) & Diosmetin \\
\hline
\end{tabular}

TABLE 2: DPPH radical scavenging assay of Xwak $(n=3)$.

\begin{tabular}{lccc}
\hline Sample & $\begin{array}{c}\text { Concentration }(\mu \mathrm{g} / \\
\mathrm{mL})\end{array}$ & $\begin{array}{c}\text { Inhibition rate } \\
(\%)\end{array}$ & $\begin{array}{c}\mathrm{IC}_{50}(\mu \mathrm{g} / \\
\mathrm{mL})\end{array}$ \\
\hline \multirow{4}{*}{ Xwak } & 156.25 & 93.01 & \\
& 78.13 & 91.66 & \\
& 39.06 & 74.24 & $21.02 \pm 0.33$ \\
& 19.53 & 47.38 & \\
Vitamin C & 9.76 & 21.26 & \\
& 25 & 93.74 & \\
& 12.5 & 86.16 & \\
& 6.25 & 57.23 & $5.18 \pm 0.29$ \\
\hline
\end{tabular}

TABLE 3: ABTS radical scavenging assay of Xwak $(n=3)$.

\begin{tabular}{lccc}
\hline Sample & $\begin{array}{c}\text { Concentration }(\mu \mathrm{g} / \\
\mathrm{mL})\end{array}$ & $\begin{array}{c}\text { Inhibition rate } \\
(\%)\end{array}$ & $\begin{array}{c}\mathrm{IC}_{50}(\mu \mathrm{g} / \\
\mathrm{mL})\end{array}$ \\
\hline \multirow{4}{*}{ Xwak } & 50 & 99.75 & \\
& 25 & 64.24 & \\
& 12.5 & 35.28 & $14.39 \pm 0.30$ \\
& 6.25 & 18.92 & \\
Vitamin C & 3.13 & 11.25 & \\
& 8 & 97.79 & \\
& 6 & 74.80 & \\
& 2 & 49.12 & $3.26 \pm 0.36$ \\
\hline
\end{tabular}

\section{Discussion}

Oxidative stress plays a significant role in the pathogenesis of alcoholic liver injury. The metabolism of ethanol to acetaldehyde and then to acetate is associated with the production of reactive oxygen species (ROS) accentuating the oxidative state of cells $[32,33]$. In the present study, we evaluated the scavenging effects of Xwak on free radicals of ABTS and DPPH in vitro, and the results showed that Xwak has a satisfactory antioxidant activity and can be used as a potential free radical scavenger. Therefore, we further studied the antioxidant and anti-inflammatory activities of Xwak in the mouse model of alcoholic liver injury, in order to clarify its hepatoprotective mechanism.
The alanine aminotransferase (ALT) and aspartate aminotransferase (AST) are both found in serum, in the liver, and in various organ tissues. Transaminases are rapidly released into blood stream when injuries or diseases affected the body tissues [34]. The results of the present study unveiled that the levels of AST, ALT, and ALP in the mouse model of acute alcoholic liver injury were significantly increased in serum, which is consistent with findings of previous reports [35]. This indicated that the mouse model of acute alcoholic liver injury was successfully established. Furthermore, we measured the increased levels of AST and ALT in the liver, but they are not as significant as they are in serum, and these results showed that acute alcoholic liver injury can cause a rapidly increased transaminase levels in serum, while the levels of transaminase in the liver were increased slowly, but both serum and liver transaminase levels were improved by Xwak extract treatment. Moreover, the increased levels of NO and LDH in the liver of mice were also reduced by Xwak. These data suggested that Xwak could improve liver function in mice with alcoholic liver injury.

Ethanol treatment leads to the production of a great number of ROS and then enhances oxidative stress in body tissues. A variety of enzymatic and nonenzymatic systems participate in protecting cells from ROS, such as CAT, GSHPX, and T-SOD [36]. The levels of CAT, GSH-PX, and T-SOD were measured in the mouse model of alcoholic liver injury. The results showed that the activities of these three enzymes were significantly reduced in the mouse model of alcoholic liver injury. Treatment with Xwak noticeably improved the activities of CAT, GSH-PX, and T-SOD. MDA is one of the most known secondary products of lipid peroxidation, and it can be used as a marker of cell membrane injury. The results of the current research uncovered that the level of MDA was significantly reduced after treatment with Xwak. The abovementioned results showed that Xwak could alleviate the oxidative stress-induced liver injury through antioxidant activity.

Hepatoprotective cytokines, e.g., IL-6, are associated with ALD [37]. The production of TNF- $\alpha$ is one of the earliest events in several types of liver injuries [38]. In addition, TNF- $\alpha$ can induce other cytokines, such as IL-6, and recruit more inflammatory cells to damage the hepatocytes. TGF- $\beta$ is a multifunctional cytokine involved in various pathologic conditions, including carcinogenesis and tissue 


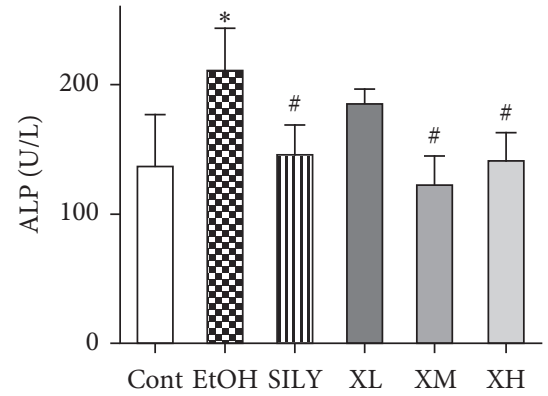

(a)

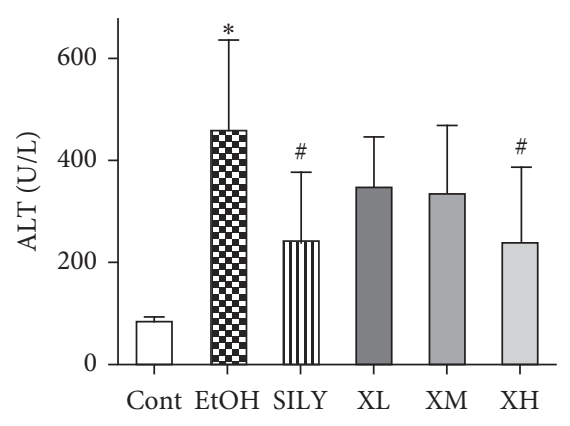

(b)

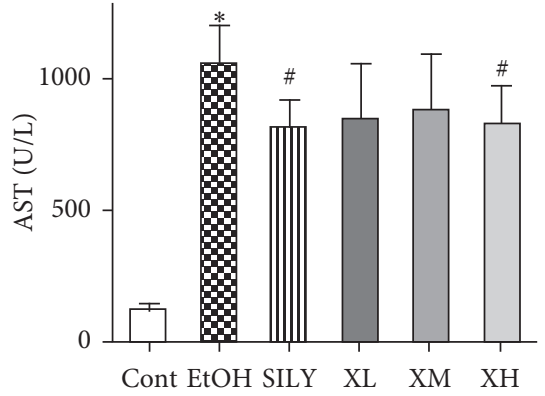

(c)

Figure 1: Effects of Xwak on the serum levels of alkaline phosphatase (ALP), alanine aminotransferase (ALT), and aspartate aminotransferase (AST). Data are expressed as the mean \pm standard deviation (SD) $(n=8) .{ }^{*} p<0.05$ compared with the Cont; ${ }^{\#} p<0.05$ compared with the EtOH. Cont, control group; EtOH, model group; SILY, positive control; XL (low-dose of Xwak); XM, medium-dose of Xwak; XH, high-dose of Xwak.

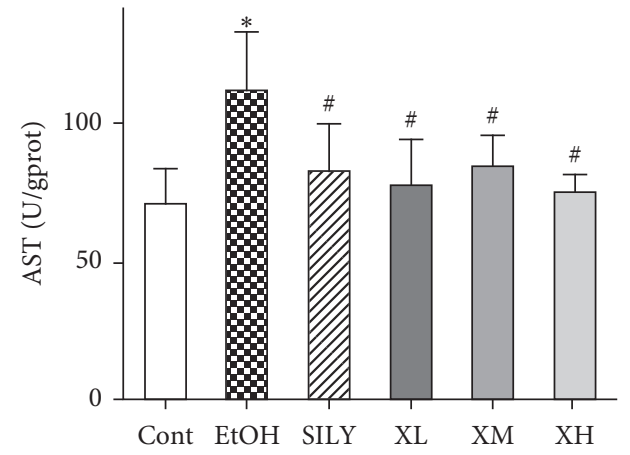

(a)

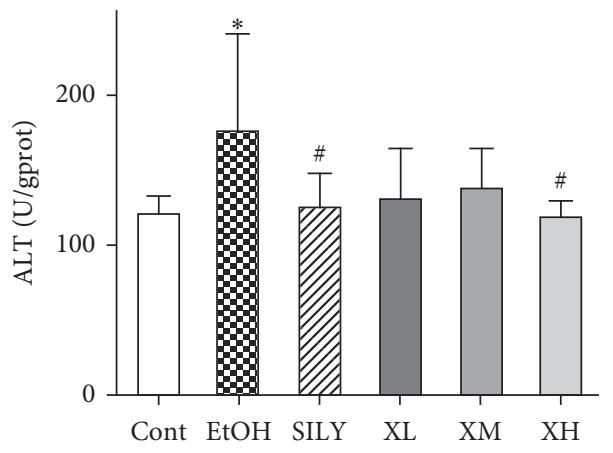

(b)

FIGURE 2: Effects of Xwak on aspartate aminotransferase (AST) and alanine aminotransferase (ALT) in the liver of mice. Values are expressed as the mean \pm standard deviation (SD) $(n=8) .{ }^{*} p<0.05$ compared with the Cont group; ${ }^{\#} p<0.05$ compared with the EtOH group. Cont, control group; EtOH, model group; SILY, positive control; XL, low-dose of Xwak; XM, medium-dose of Xwak; XH, high-dose of Xwak.

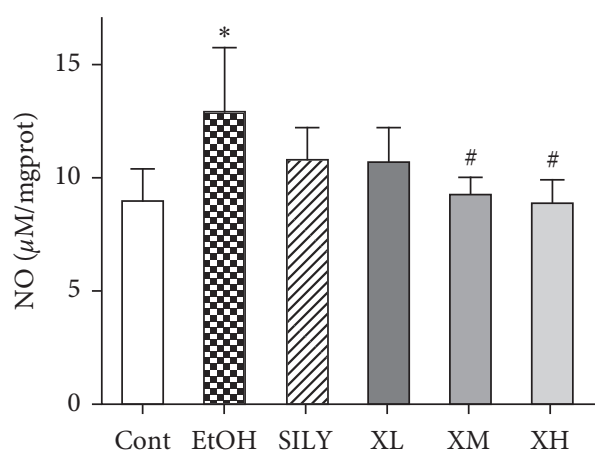

(a)

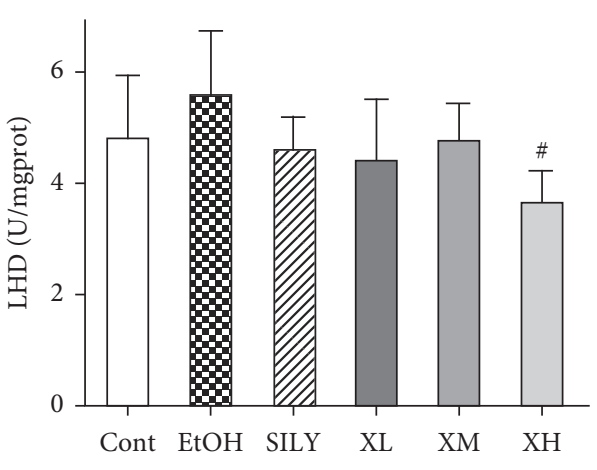

(b)

FIGURE 3: Effects of Xwak on the levels of nitric oxide (NO) and lactate dehydrogenase (LDH) in the liver of mice. Values are expressed as the mean \pm standard deviation (SD) $(n=8) .{ }^{*} p<0.05$ compared with the Cont group; ${ }^{\#} p<0.05$ compared with the EtOH group. Cont, control group; EtOH, model group; SILY, positive control; XL, low-dose of Xwak; XM, medium-dose of Xwak; XH, high-dose of Xwak.

fibrosis [39]. We, in the present research, measured the levels of three important cytokines (TNF- $\alpha$, TGF- $\beta$, and IL-6). It was revealed that the levels of TNF- $\alpha$ and TGF- $\beta$ were increased in the mouse model of alcoholic liver injury, which accompanied with inflammation-mediated disruption. However, the levels of pro-inflammatory cytokines were 


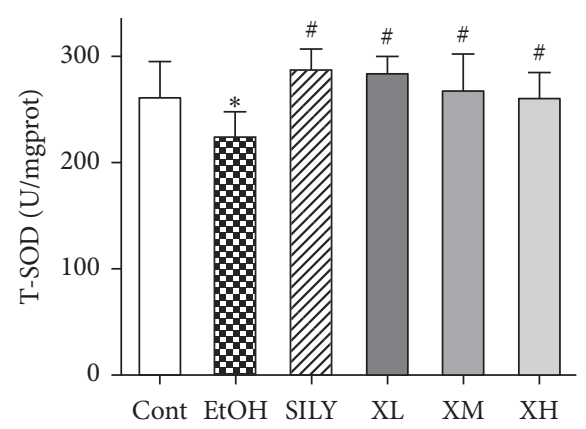

(a)

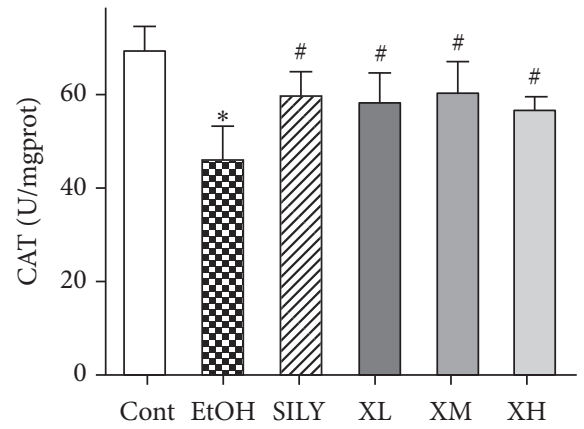

(c)

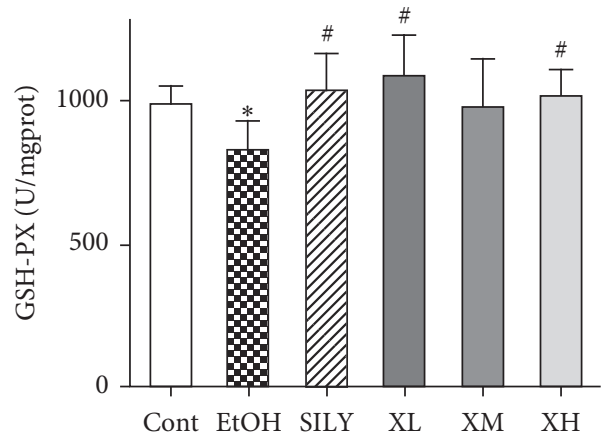

(b)

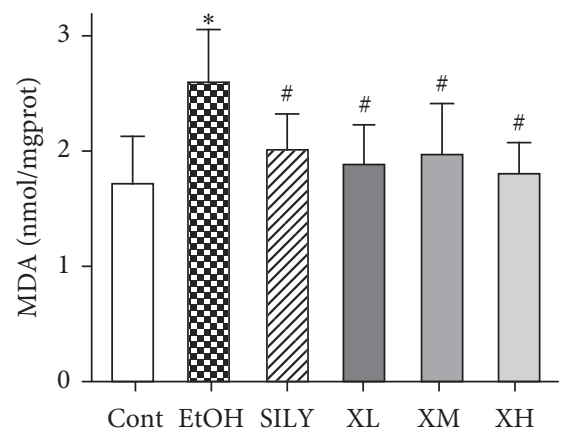

(d)

FIgURE 4: Effects of Xwak on the levels of total superoxide dismutase (T-SOD), glutathione peroxidase (GSH-PX), catalase (CAT), and malondialdehyde (MDA) in the liver of mice. Data are expressed as the mean \pm standard deviation (SD) $(n=8) .{ }^{*} p<0.05$ compared with the Cont group; ${ }^{\#} p<0.05$ compared with the EtOH group. Cont, control group; EtOH, model group; SILY, positive control; XL, low-dose of Xwak; XM, medium-dose of Xwak; XH, high-dose of Xwak.

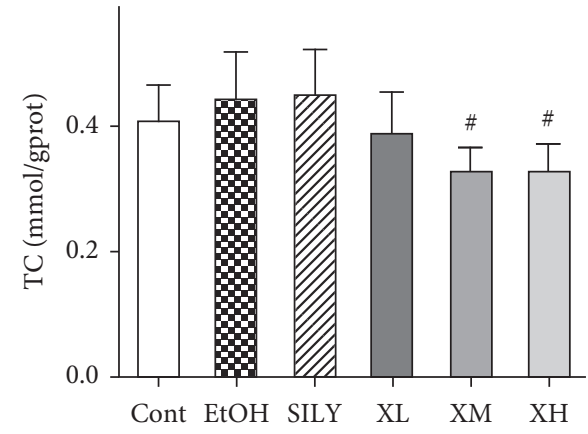

(a)

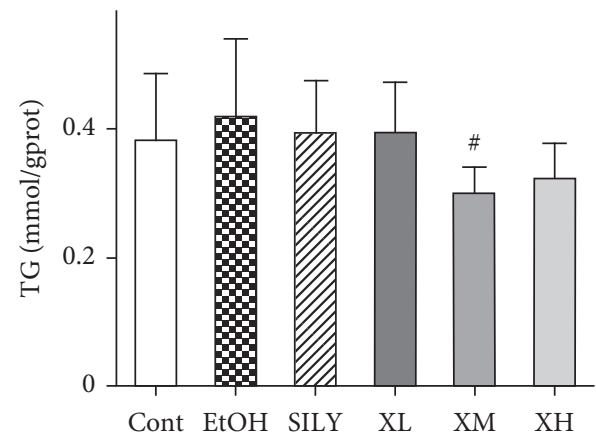

(b)

Figure 5: Effects of Xwak on the levels of total cholesterol (TC) and triglyceride (TG) in the liver of mice. Values are expressed as the mean \pm standard deviation (SD) $(n=8) .{ }^{*} p<0.05$ compared with the Cont group; ${ }^{\#} p<0.05$ compared with the EtOH group. Cont, control group; EtOH, model group; SILY, positive control; XL, low-dose of Xwak; XM, medium-dose of Xwak; XH, high-dose of Xwak.

improved in the mouse model of alcoholic liver injury after treatment with Xwak. The improvement of inflammationmediated disruption may conducive to the Xwak activity in the control of liver injury.

ERKs are widely expressed protein kinase intracellular signaling molecules, and a number of studies demonstrated that ERK plays a substantial role in liver diseases [40-42]. The association between ERK and NF- $\kappa \mathrm{B}$ pathways in response to inflammatory signals regulates several inflammatory factors, such as TNF- $\alpha$, NO, iNOS, and COX2 [43-45]. Treatment with Xwak amended the high expression levels of p-ERK, p-NF- $\kappa \mathrm{B}$, iNOS, and COX-2 in the mouse model of alcoholic liver injury. The activation of the ERK/NF- $\kappa \mathrm{B}$ signal pathway was accompanied with the improvement of some inflammatory factors, and the levels of TNF- $\alpha$, TGF- $\beta$, IL- 6 , and NO were also ameliorated in the mouse model of alcoholic liver injury after treatment with Xwak. 


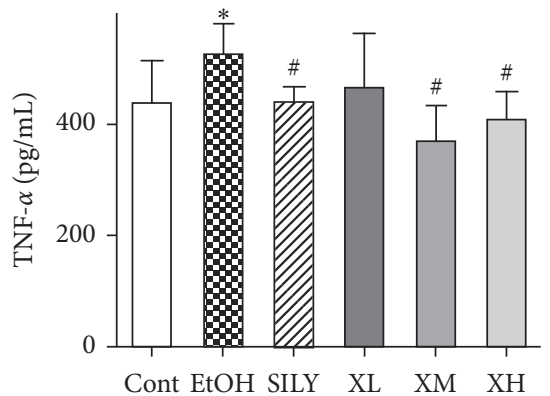

(a)

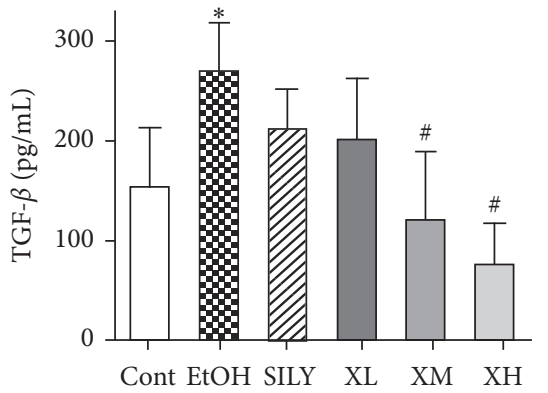

(b)

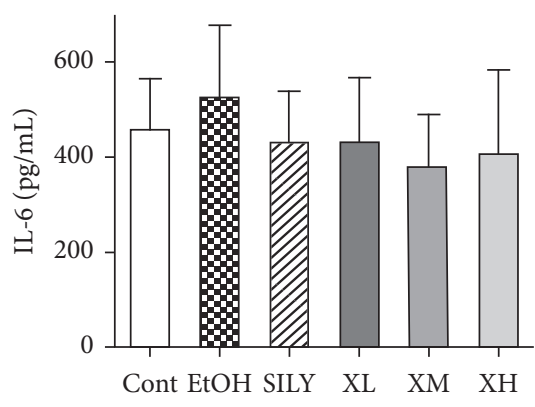

(c)

Figure 6: Effects of Xwak on the levels of tumor necrosis factor- $\alpha$ (TNF- $\alpha$ ), transforming growth factor- $\beta$ (TGF- $\beta$ ), and interleukin-6 (IL-6) in the liver of mice. Values are expressed as the mean \pm standard deviation (SD) $(n=8) .{ }^{*} p<0.05$ compared with the Cont group; ${ }^{\#} p<0.05$ compared with the EtOH group. Cont, control group; EtOH, model group; SILY, positive control; XL, low-dose of Xwak; XM, medium-dose of Xwak; XH, high-dose of Xwak.

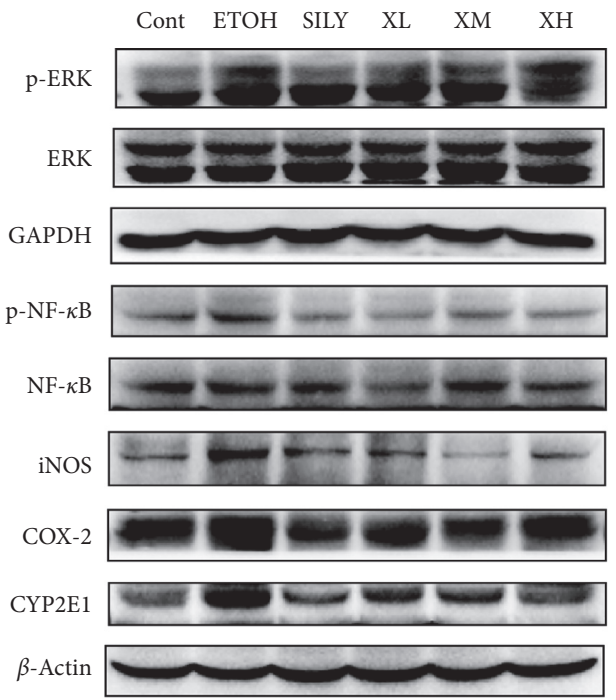

(a)

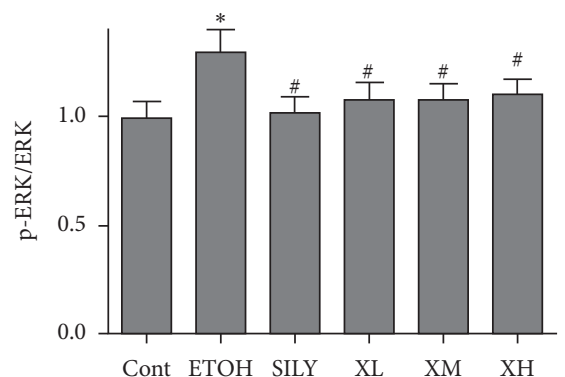

(c)

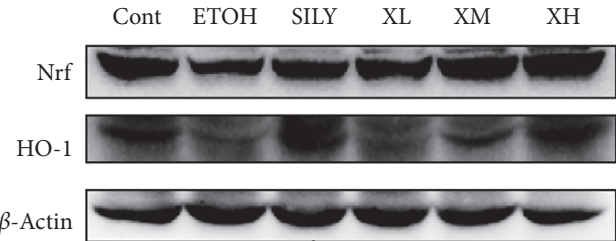

(b)

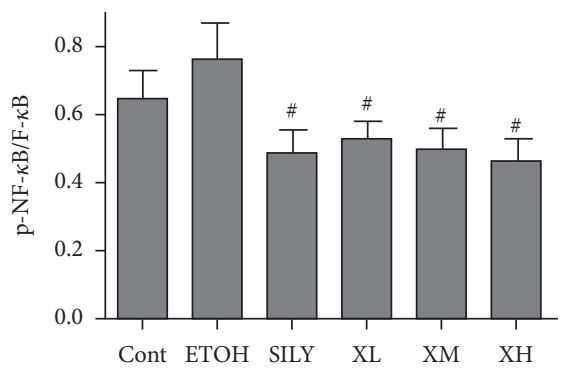

(d)

Figure 7: Continued. 


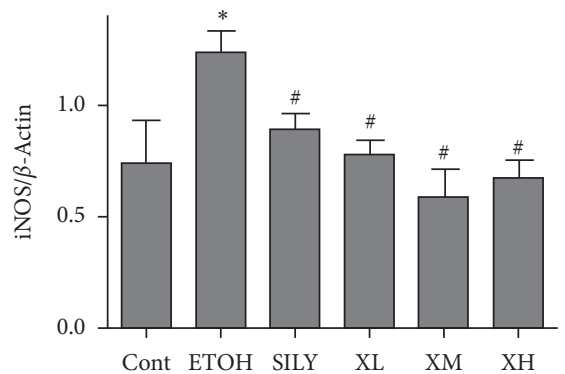

(e)

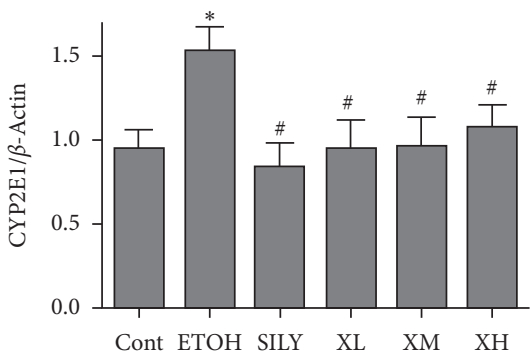

(g)

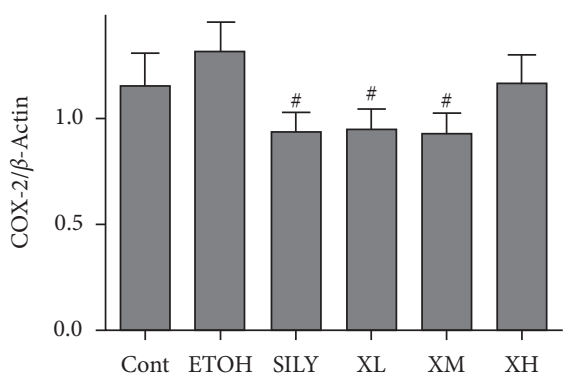

(f)

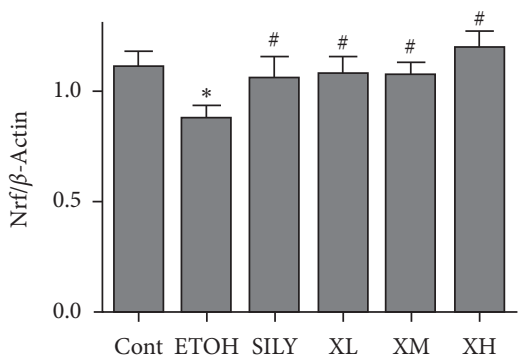

(h)

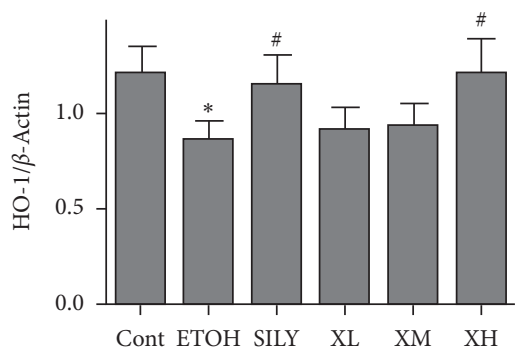

(i)

Figure 7: Effects of Xwak on protein expression level were measured by Western blot analysis. (a) The bands of ERK/NF- $\kappa \mathrm{B}$ signaling pathways. (b) The bands of Nrf/HO-1 signaling pathways. Quantification of different protein expressions. (c) Quantification of p-ERK/ERK, (d) quantification of $\mathrm{p}-\mathrm{NF}-\kappa \mathrm{B} / \mathrm{NF}-\kappa \mathrm{B}$, (e) quantification of iNOS/ $\beta$-actin, (f) quantification of COX-2/ $\beta$-actin, (g) quantification of CYP2E1/ $\beta$-actin, (h) quantification of $\mathrm{Nrf} 2 / \beta$-actin, and (i) quantification of $\mathrm{HO}-1 / \beta$-actin. Values are expressed as the mean \pm standard deviation (SD). Cont, control group; EtOH, model group; SILY, positive control; XL, low-dose of Xwak; XM, medium-dose of Xwak; XH, high-dose of Xwak.

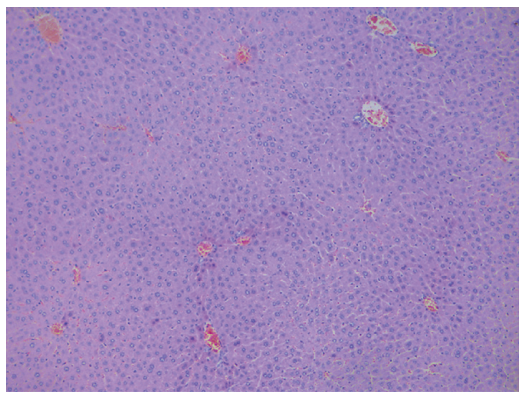

(a)

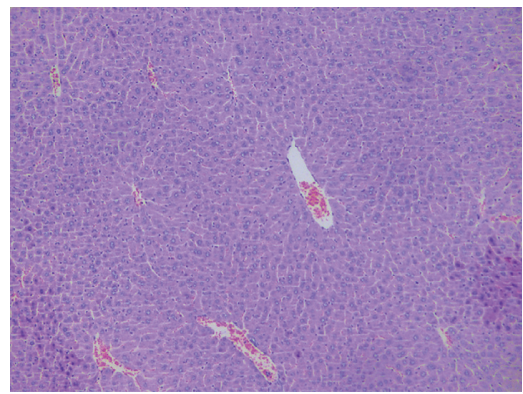

(b)

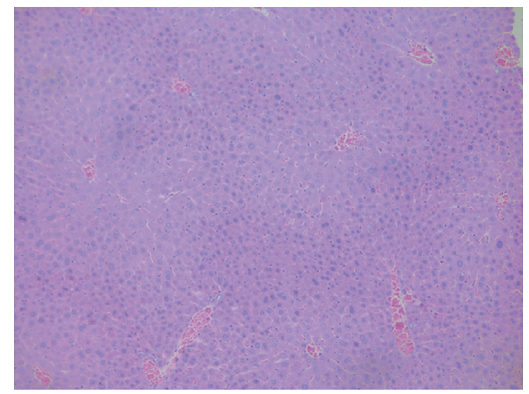

(c)

FIGURE 8: Continued. 


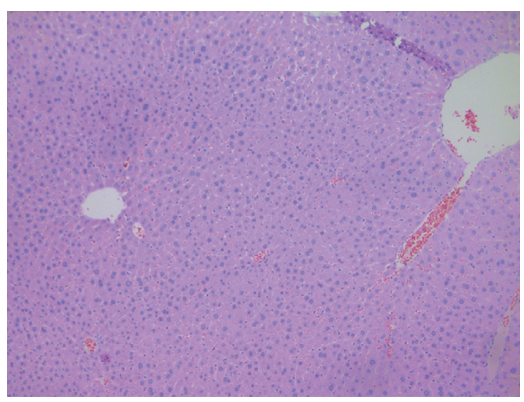

(d)

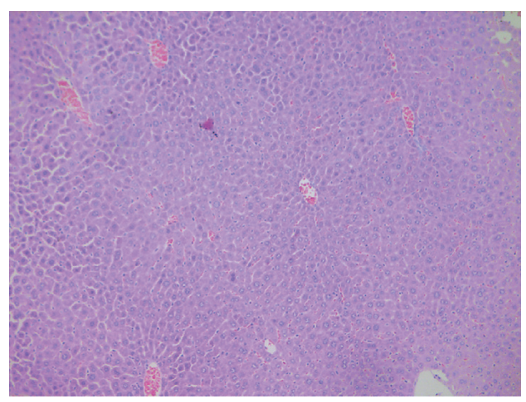

(e)

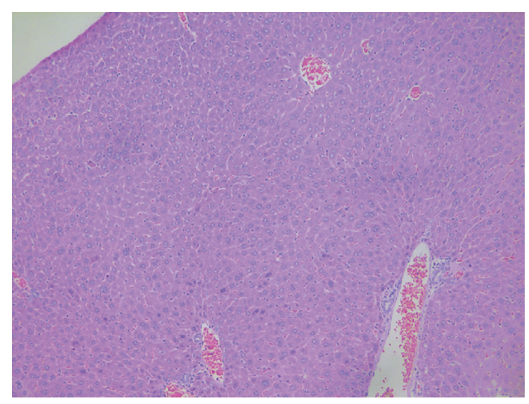

(f)

FIGURE 8: Effects of Xwak on liver histopathology. (a) Cont (control group), (b) EtOH (model group), (c) SILY (positive control), (d) XL (low-dose of Xwak), (e) XM (medium-dose of Xwak), and (f) XH (high-dose of Xwak).

Anti-inflammatory and antioxidants agents are often considered beneficial in the treatment of liver diseases. The main compounds of Xwak are chlorogenic acid and flavonoids, and these compounds were found to have the effect of controlling oxidative and inflammatory stress conditions, which is also consistent with our results $[10,46]$. CYP2E1 is one of the major ROS generators in the liver and is recognized as a risk factor for alcoholic liver disease [47-49]. Some studies previously indicated that the Nrf2/HO-1 signaling pathway is involved in the mechanism of antioxidation, anti-inflammation, and cell protection [50-53]. The results of the current research showed that the expression level of CYP2E1 was inhibited, and the Nrf2/HO-1 signaling pathway was activated in the mouse model of alcoholic liver injury after treatment with Xwak. Moreover, the activity of antioxidant enzyme improved. The state of oxidative stress in the mouse model of alcoholic liver injury was alleviated by Xwak.

The change of biochemical indexes in liver function is that the body has started the compensation mechanism (selfprotection), which can protect the body from damage when the external low-intensity stimulation. In the case of functional decompensation, cell damage will be shown and there will be obvious changes in morphology. Since we used the model of acute liver injury induced by intraperitoneal injection, the animals were killed 5 hours after injection, and the relevant indexes were detected. Therefore, there was no obvious morphological change in the liver, so no obvious histopathological changes were observed in the section.

Based on the experimental results, the medium-dose and high-dose of Xwak have shown the hepatoprotective effect in acute alcoholic liver injury mice and similar to silybin potency. The dose of Xwak administered is larger than silybin, which is calculated based on the specifications of clinical medications. Therefore, compared with the positive drug silybin, as a classic folk prescription, Xwak has a certain hepatoprotective effect in acute alcoholic liver injury mice. Furthermore, some of the detection indexes in this study will be carried out in the follow-up experiments.

In conclusion, our findings showed hepatoprotective influence of Xwak through activation of ERK/NF- $\kappa$ B and Nrf2/HO-1 signaling pathways to regulate the redox balance and reduce the oxidative stress-induced inflammatory response. This study may provide a reliable scientific basis for the clinical application of Xwak.

\section{Data Availability}

Derived data supporting the findings of this study are available from the corresponding author upon a reasonable request.

\section{Conflicts of Interest}

The authors declare that there are no conflicts of interest.

\section{Acknowledgments}

This research was financially supported by the West Light Foundation of the Chinese Academy of Sciences (grant no. 2019-XBQNXZ-B-012) and Central Asian Drug Discovery and Development Center of Chinese Academy of Sciences.

\section{Supplementary Materials}

LC-MS analysis of Xwak. (Supplementary Materials)

\section{References}

[1] H. K. Seitz, R. Bataller, H. Cortez-Pinto et al., "Alcoholic liver disease," Nature Reviews Disease Primers, vol. 4, no. 1, pp. 1-22, 2018.

[2] J. S. Bajaj, "Alcohol, liver disease and the gut microbiota," Nature Reviews Gastroenterology \& Hepatology, vol. 16, no. 4, pp. 235-246, 2019.

[3] G. Askgaard, M. S. Kjær, and J. S. Tolstrup, "Opportunities to prevent alcoholic liver cirrhosis in high-risk populations," The American Journal of Gastroenterology, vol. 114, no. 2, pp. 221-232, 2019.

[4] W.-J. Wang, P. Xiao, H.-Q. Xu, J.-Q. Niu, and Y.-H. Gao, "Growing burden of alcoholic liver disease in China: a review," World Journal of Gastroenterology, vol. 25, no. 12, pp. 1445-1456, 2019.

[5] W. E. Rodriguez, B. Wahlang, Y. Wang et al., "Phosphodiesterase 4 inhibition as a therapeutic target for alcoholic liver disease: from bedside to bench," Hepatology, vol. 70, no. 6, pp. 1958-1971, 2019. 
[6] A. Zhang and P. Mathurin, "Alcoholic liver disease: mechanisms of injury and targeted treatment," Nature Reviews Gastroenterology \& Hepatology, vol. 12, no. 4, pp. 231-242, 2015.

[7] A. K. Singal and V. H. Shah, "Current trials and novel therapeutic targets for alcoholic hepatitis," Journal of Hepatology, vol. 70, no. 2, pp. 305-313, 2019.

[8] H. Cichoż-Lach and A. Michalak, "Oxidative stress as a crucial factor in liver diseases," World Journal of Gastroenterology, vol. 20, no. 25, pp. 8082-8091, 2014.

[9] E. Ceni, T. Mello, and A. Galli, "Pathogenesis of alcoholic liver disease: role of oxidative metabolism," World Journal of Gastroenterology, vol. 20, no. 47, pp. 17756-17772, 2014.

[10] Y. Tu, S. Zhu, J. Wang, E. Burstein, and D. Jia, "Natural compounds in the chemoprevention of alcoholic liver disease," Phytotherapy Research, vol. 33, no. 9, pp. 2192-2212, 2019.

[11] L.-Z. Kong, N. Chandimali, Y.-H. Han et al., "Pathogenesis, early diagnosis, and therapeutic management of alcoholic liver disease," International Journal of Molecular Sciences, vol. 20, no. 11, p. 2712, 2019.

[12] X. Lee, S. Li, Y. Li, R. Y. Gan, and H. B. Li, “Gut microbiota's relationship with liver disease and role in hepatoprotection by dietary natural products and probiotics," Nutrients, vol. 10, no. 10, 2018.

[13] A. Zhang, Y. Yang, Y. Wang et al., “Adjuvant-active aqueous extracts from Artemisia rupestris L. improve immune responses through TLR4 signaling pathway," Vaccine, vol. 35, no. 7, pp. 1037-1045, 2017.

[14] F. Zhao, A. Zhang, D. Wang, J. Li, F. Gao, and X. Fan, “The effect of aqueous extract of Xinjiang Artemisia rupestris L. (an influenza virus vaccine adjuvant) on enhancing immune responses and reducing antigen dose required for immunity," PLoS One, vol. 12, no. 8, 2017.

[15] C. Zhang, S. Wang, K.-W. Zeng et al., "Nitric oxide inhibitory dimeric sesquiterpenoids from Artemisia rupestris," Journal of Natural Products, vol. 79, no. 1, pp. 213-223, 2015.

[16] J. Li, H. Dong, M. Yan et al., "New guaiane sesquiterpenes from Artemisia rupestris and their inhibitory effects on nitric oxide production," Bioorganic \& Medicinal Chemistry Letters, vol. 24, no. 18, pp. 4435-4438, 2014.

[17] Q. Zhu, X. Zhao, L. Yin et al., "The essential oil of Artemisia capillaris protects against CCl4-induced liver injury in vivo," Revista Brasileira de Farmacognosia, vol. 26, no. 3, pp. 369374, 2016.

[18] J.-M. Zhang, H.-G. Kim, M.-K. Choi et al., "Artemisia capillaris extract protects against bile duct ligation-induced liver fibrosis in rats," Experimental and Toxicologic Pathology, vol. 65, no. 6, pp. 837-844, 2013.

[19] X. Lee, W. Yang, M. Yasen, H. Zhao, and H. a. Aisa, "The mechanism of hepatoprotective effect of sesquiterpene rich fraction from Cichorum glandulosum Boiss. et Huet on immune reaction-induced liver injury in mice," Journal of Ethnopharmacology, vol. 155, no. 2, pp. 1068-1075, 2014.

[20] D.-M. Qin, X.-B. Wang, N. Zou, C. Han, and J. Xu, "Gas Chromatography-Mass Spectrometry (GC-MS) Analysis of the Volatile Oil of Cichorium Glandulosum Boiss et Huet and its Effects on Carbon Tetrachloride-Induced Liver Fibrosis in Rats," Medical Science Monitor, vol. 25, pp. 3591-3604, 2019.

[21] M. Yang, X. Li, X. Zeng et al., "Rheum palmatum L. Attenuates high fat diet-induced hepatosteatosis by activating AMP-activated protein kinase," The American Journal of Chinese Medicine, vol. 44, no. 3, pp. 551-564, 2016.
[22] P. Ou, A. D. Talukdar, R. Nath et al., "Role of natural phenolics in hepatoprotection: a mechanistic review and analysis of regulatory network of associated genes," Frontiers in Pharmacology, vol. 10, 2019.

[23] O. Karimi-Khouzani, E. Heidarian, and S. A. Amini, "Antiinflammatory and ameliorative effects of gallic acid on fluoxetine-induced oxidative stress and liver damage in rats," Pharmacological Reports, vol. 69, no. 4, pp. 830-835, 2017.

[24] W. Xie, M. Wang, C. Chen, X. Zhang, and M. F. Melzig, "Hepatoprotective effect of isoquercitrin against acetaminophen-induced liver injury," Life Sciences, vol. 152, pp. 180189, 2016.

[25] S. Li, H. Y. Tan, N. Wang, F. Cheung, M. Hong, and Y. Feng, "The potential and action mechanism of polyphenols in the treatment of liver diseases," Oxidative Medicine and Cellular Longevity, vol. 2018, Article ID 8394818, 25 pages, 2018.

[26] F. Salomone, F. Galvano, and G. Li Volti, "Molecular bases underlying the hepatoprotective effects of coffee," Nutrients, vol. 9, no. 1, 2017.

[27] X. Wang, M. Liu, C. Zhang et al., "Antioxidant activity and protective effects of enzyme-extracted oudemansiella radiata polysaccharides on alcohol-induced liver injury," Molecules, vol. 23, no. 2, 2018.

[28] L. Liu, D. Tang, H. Zhao, X. Xin, and H. A. Aisa, "Hypoglycemic effect of the polyphenols rich extract from Rose rugosa Thunb on high fat diet and STZ induced diabetic rats," Journal of Ethnopharmacology, vol. 200, pp. 174-181, 2017.

[29] T. T. James, A. R. Aroor, R. W. Lim, and S. D. Shukla, "Histone H3 phosphorylation (Ser10, Ser28) and phosphoacetylation (K9S10) are differentially associated with gene expression in liver of rats treated in vivo with acute ethanol," Journal of Pharmacology and Experimental Therapeutics, vol. 340, no. 2, pp. 237-247, 2012.

[30] S. Wang, S. Sui, Z. Liu et al., "Protective roles of hepatic gamma-aminobutyric acid signaling in acute ethanol exposure-induced liver injury," Journal of Applied Toxicology, vol. 38, no. 3, pp. 341-350, 2018.

[31] H. Peng, L. Lou, D. Zhang et al., "Qiliqiangxin capsule improves cardiac function and attenuates cardiac remodeling by upregulating miR-133a after myocardial infarction in rats," Evidence-Based Complementary and Alternative Medicine, vol. 2019, Article ID 7528214, 9 pages, 2019.

[32] D. Zhao and A. Cederbaum, "Oxidative stress and alcoholic liver disease," Seminars in Liver Disease, vol. 29, no. 2, pp. 141-154, 2009.

[33] G. E. Arteel, "Oxidants and antioxidants in alcohol-induced liver disease," Gastroenterology, vol. 124, no. 3, pp. 778-790, 2003.

[34] O. C. Ejelonu, O. O. Elekofehinti, and I. G. Adanlawo, "Tithonia diversifolia saponin-blood lipid interaction and its influence on immune system of normal wistar rats," Biomedicine \& Pharmacotherapy, vol. 87, pp. 589-595, 2017.

[35] Y. Zheng, J. Cui, A.-H. Chen, Z.-M. Zong, and X.-Y. Wei, "Optimization of ultrasonic-microwave assisted extraction and hepatoprotective activities of polysaccharides from trametes orientalis," Molecules, vol. 24, no. 1, p. 147, 2019.

[36] A. I. Cederbaum, Y. Lu, and D. Wu, "Role of oxidative stress in alcohol-induced liver injury," Archives of Toxicology, vol. 83, no. 6, pp. 519-548, 2009.

[37] J. Liu, "Ethanol and liver: recent insights into the mechanisms of ethanol-induced fatty liver," World Journal of Gastroenterology, vol. 20, no. 40, p. 14672, 2014. 
[38] H. Tilg and A. M. Diehl, "Cytokines in alcoholic and nonalcoholic steatohepatitis," New England Journal of Medicine, vol. 343, no. 20, pp. 1467-1476, 2000.

[39] J. Massagué, "TGF $\beta$ in cancer," Cell, vol. 134, no. 2, pp. 215-230, 2008.

[40] B. Foglia, S. Cannito, C. Bocca, M. Parola, and E. Novo, "ERK pathway in activated, myofibroblast-like, hepatic stellate cells: a critical signaling crossroad sustaining liver fibrosis," International Journal of Molecular Sciences, vol. 20, no. 11, p. 2700, 2019.

[41] G. K. Gerresheim, E. Roeb, A. M. Michel, and M. Niepmann, "Hepatitis $\mathrm{C}$ virus downregulates core subunits of oxidative phosphorylation, reminiscent of the warburg effect in cancer cells," Cells, vol. 8, no. 11, p. 1410, 2019.

[42] R. Moreau, A. Périanin, and V. Arroyo, "Review of defective NADPH oxidase activity and myeloperoxidase release in neutrophils from patients with cirrhosis," Frontiers in Immunology, vol. 10, 2019.

[43] P. Sun, S. Z. Song, S. Jiang et al., "Salidroside regulates inflammatory response in raw 264.7 macrophages via TLR4/ TAK1 and ameliorates inflammation in alcohol binge drinking-induced liver injury," Molecules, vol. 21, no. 11, 2016.

[44] J. Li, H. Li, Y. Yu et al., "Mannan-binding lectin suppresses growth of hepatocellular carcinoma by regulating hepatic stellate cell activation via the ERK/COX-2/PGE2 pathway," Oncoimmunology, vol. 8, no. 2, 2019.

[45] Q. Yu, L. Wu, T. Liu et al., "Protective effects of levo-tetrahydropalmatine on hepatic ischemia/reperfusion injury are mediated by inhibition of the ERK/NF- $\kappa \mathrm{B}$ pathway," International Immunopharmacology, vol. 70, pp. 435-445, 2019.

[46] N. Li and D. D. Kitts, "Role of chlorogenic acids in controlling oxidative and inflammatory stress conditions," Nutrients, vol. 8, no. 1, 2015.

[47] T. M. Leung and Y. Lu, "Alcoholic liver disease: from CYP2E1 to CYP2A5," Current Molecular Pharmacology, vol. 10, no. 3, pp. 172-178, 2017.

[48] Y. Lu and A. I. Cederbaum, "Cytochrome P450s and alcoholic liver disease," Current Pharmaceutical Design, vol. 24, no. 14, pp. 1502-1517, 2018.

[49] M. A. Abdelmegeed, S.-K. Ha, Y. Choi, M. Akbar, and B.-J. Song, "Role of CYP2E1 in mitochondrial dysfunction and hepatic injury by alcohol and non-alcoholic substances," Current Molecular Pharmacology, vol. 10, no. 3, pp. 207-225, 2017.

[50] S. Habtemariam, "The Nrf2/HO-1 Axis as targets for flavanones: neuroprotection by pinocembrin, naringenin, and eriodictyol," Oxidative Medicine and Cellular Longevity, vol. 2019, Article ID 4724920, 15 pages, 2019.

[51] D. Xu, M. Xu, S. Jeong et al., "The role of Nrf2 in liver disease: novel molecular mechanisms and therapeutic approaches," Frontiers in Pharmacology, vol. 9, 2019.

[52] G. Carota, M. Raffaele, V. Sorrenti, L. Salerno, V. Pittalà, and S. Intagliata, "Ginseng and heme oxygenase-1: the link between an old herb and a new protective system," Fitoterapia, vol. 139, p. 104370, 2019.

[53] P. Rajput, A. Jangra, M. Kwatra, A. Mishra, and M. Lahkar, "Alcohol aggravates stress-induced cognitive deficits and hippocampal neurotoxicity: protective effect of melatonin," Biomedicine \& Pharmacotherapy, vol. 91, pp. 457-466, 2017. 